\title{
Implementation of the Ottawa Ankle Rules by nurses working in an accident and emergency department
}

Peter Salt, Michael Clancy

\begin{abstract}
Objective-To assess whether accident and emergency (A\&E) nurses using the Ottawa Ankle Rules could detect all ankle fractures.

Design-Prospective observational study. Setting-A\&E department of a university teaching hospital.

Subjects-All patients who presented with ankle injuries who were initially assessed by a nurse taught the Ottawa Ankle Rules. Outcome measures-(1) The numbers of patients referred by the nurse for ankle radiography; (2) of these, the number with ankle fractures; (3) of those not sent for radiography initially by the nurse, the number who subsequently had $x$ rays (ordered by the doctor) and had a fracture; (4) of those having no $x$ rays, the number who reattended later.

Results-324 patients were eligible; 238 had $x$ rays at the request of the nurse $(73 \%) ; 48$ of these $(20 \%)$ were diagnosed as having a fracture. Of those 86 patients not sent for radiography by the nurse, 19 subsequently had $x$ ray examinations at the request of a doctor and no fracture was detected. Of the 67 not sent for radiography, none returned within the subsequent eight weeks.
\end{abstract}

Conclusions-Nurses can apply the Ottawa Ankle Rules safely without missing acute fractures; that is, of those who were not sent for radiography by nurses, none subsequently reattended the $A \& E$ department or the trauma service of the Bristol Royal Infirmary during the following two months.

$(\mathcal{F}$ Accid Emerg Med 1997;14:363-365)

Keywords: Ottawa Ankle Rules; nurses; ankle fracture

Ankle injuries are a common complaint among patients attending accident and emergency (A\&E) departments and most are sent for radiography, with a low rate of fracture detection..$^{1-6}$ In our own department, these comprise approximately $5 \%$ of the workload and a previous audit (before the introduction of any $x$ ray rules) of 438 patients suffering inversion ankle injuries showed that $81 \%$ had $x$ rays (ordered by both nurses and doctors) and yet in only $8 \%$ was a fracture detected. The Ottawa Ankle Rules, a series of decision rules for the use of $x$ rays in acute ankle injuries, have been developed, validated, and are highly sensitive in identifying fractures. ${ }^{7-10}$ They have proved successful in a variety of settings with different clinicians ${ }^{10}$ and have led to a decrease in the use

\author{
Accident and \\ Emergency \\ Department, Bristol \\ Royal Infirmary, \\ Bristol, UK \\ P Salt \\ M Clancy \\ Correspondence to: \\ Mr Michael J Clancy, \\ Consultant in Accident and \\ Emergency Medicine, \\ Southampton General \\ Hospital, Tremona Road, \\ Southampton SO16 6YD, \\ UK.
}

Accepted for publication 18 July 1997

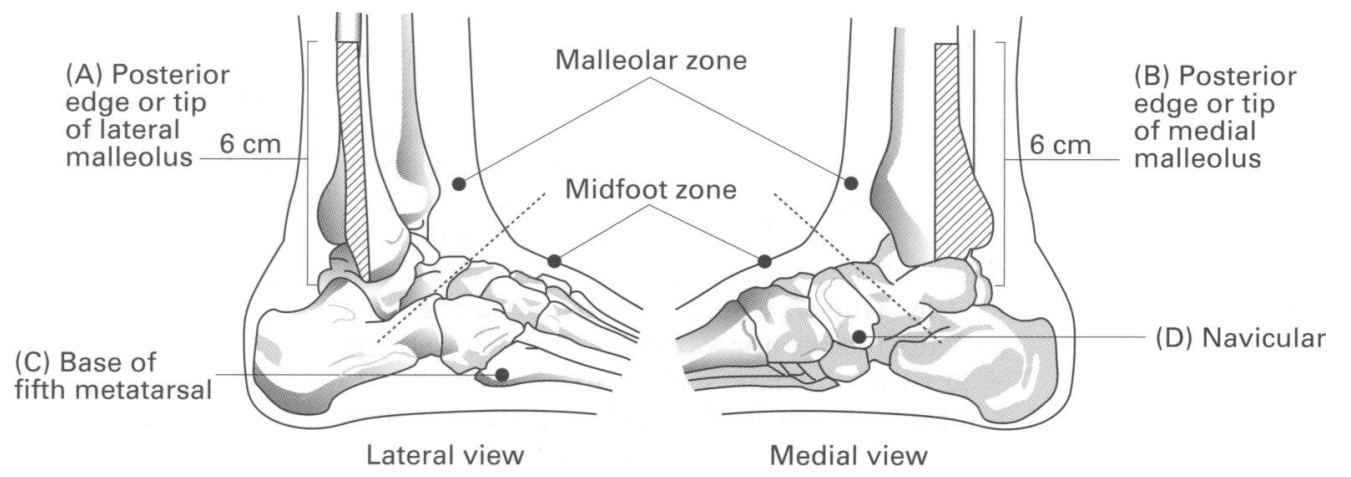

An ankle radiographic series is only required if there is any pain in malleolar zone and any of these findings:

(1) Bone tenderness at $A$

(2) Bone tenderness at B or

(3) Inability to bear weight both immediately and in emergency department

Figure 1 The Ottawa Ankle Rules.
A foot radiographic series is only required if there is any pain in midfoot zone and any of these findings:

(1) Bone tenderness at C

(2) Bone tenderness at $D$ or

(3) Inability to bear weight both immediately and in emergency department 


\section{Ankle injuries}

Your triage nurse or doctor has decided that you have a bruise or sprain (stretching or partial tear of ligaments) of your ankle or foot and that you do not need a plaster. If no $\mathrm{X}$-rays were ordered this was because clinical research on thousands of patients has shown that patients with the same findings as you, do not have a fracture (broken bone).

\section{What to expect:}

You may have pain when you walk for 1 to 2 weeks. It is normal for the ankle to swell up. A purple colour may appear after several days. The swelling and purple colour may last several weeks. This is normal and you should not be alarmed.

\section{However we ask you to return to the Accident \&} Emergency Department if:

- Your pain or ability to walk becomes worse after 2 days;

- Your pain or ability to walk is no better after 5 days;

You are unable to walk without assistance after 2 days;

- You have not been able to return to normal daily activities (excluding sport) by 10 days.

We have provided an information sheet called 'My ankle hurts' to explain about how you should care for your ankle, but if you are worried that your injury is not improving after 10 days, please come back to see us again. You can telephone for advice on Bristol (0117) 9283001

\section{A\&E/ANKNOX/July95}

Figure 2 Ankle information leaflet.

of ankle radiology, with patients spending less time in the emergency department, with lower costs, but without patient dissatisfaction or missed fractures. ${ }^{11}$

The rules are based on the assessment of the ability to weight bear and of areas of bone tenderness, which determine which patients are at negligible risk of fracture and do not require an $x$ ray (fig 1 ). They are easy to understand and remember.

In the United Kingdom all patients are initially assessed by a nurse and prioritised. The aim of this study was to assess whether nurses could apply the rules with a sensitivity of 1.0, which has already been shown for doctors. ${ }^{910}$ If nurses could successfully implement these rules, then other benefits (not the subject of this study) would include ensuring that patients receive appropriate $x$ rays before being seen by a clinician, leading to an even shorter total time spent in the A\&E department than already demonstrated when clinicians implement the Ottawa Ankle Rules, ${ }^{10}$ along with improved job satisfaction for nurses.

\section{Methods}

The guidance given in the paper "Implementation of the Ottawa Ankle Rules"11 was followed. Six senior nurses (previously instructed in the safe use of radiography) were individually taught the rules and given a pocket sized copy (fig 1). The rules were also displayed in the department. They were told that the rules applied to those patients who had suffered acute blunt injuries including twisting, falls from a height, blows, and vehicle accidents.

The following patient criteria led to exclusion from the study: age under 18 years; pregnant women; isolated injuries of the skin without underlying soft tissue or bone involvement; referrals from outside the hospital (for example, by general practitioners); ankle injuries occurring more than 10 days previously or patients returning for reassessment of the same injury; intoxication; head injury or multiple injuries; diminished sensation due to neurological deficit.

A printed information sheet was to be provided to patients who were not given $x$ rays, specifying when they should seek further help and encouraged to reattend this department (fig 2). This information sheet was based on that used by the Ottawa group ${ }^{10}$ (personal communication).

The decision about whether or not a fracture was present was based on the clinician's assessment of the $x$ rays. All patients not sustaining a fracture were given verbal and written advice about the management of sprained ankles. $A \& E$ doctors were instructed in the use of the rules in the same way as the nurses.

All patients initially seen by one of the six nurses and who met the entry criteria were included in the study. They were assessed using the rules and sent for $x$ ray if indicated. Those who did not have $x$ rays received an explanation of why they did not, and the doctor who subsequently saw the patient was aware that the rules had been implemented for that patient. The doctor was free to order an $x$ ray if he felt it was indicated, using the ankle rules, but was asked to tell the nurse of this decision.

For each patient the following information was recorded:

(1) Was an $x$ ray ordered by nurse?

(2) Did the $x$ ray show fracture?

(3) If $x$ ray not ordered by nurse, was one ordered by a doctor? If so, was a fracture present?

(4) If no $x$ ray done, did the patient subsequently return to the hospital, either to the A\&E department or to the trauma service, during the next two months? (This was checked by search of computerised attendance records and by highlighting the notes of those patients in whom the Ottawa rules were applied with a sticker so that if patients did return unexpectedly they could be identified and the investigators informed.)

There was no telephone follow up of patients who did not receive $x$ rays. We relied on them to follow the written guidance provided (fig 2).

\section{Results}

In all, 324 patients were subjected to the rules and $238(73 \%)$ received $x$ ray examinations. Forty eight of these $(20 \%)$ had fractures identified by the clinician. Of the remaining 86 patients, 19 were subsequently sent for $x$ ray by the doctor and no fracture was detected. Of the residual 67 patients who did not receive $x$ rays, none returned to the department in the next eight weeks. 


\section{Discussion}

Nurses were able to apply the Ottawa Ankle Rules without missing a fracture. A recent large Canadian multicentre study showed that before implementation of the rules by clinicians more than $80 \%$ of patients received $x$ rays; after implementation this dropped to $60 \% .^{9}$ Our frequency of $73 \%$ for nurses requesting $x$ rays shows an intermediate effect.

\section{CONCLUSIONS}

The Ottawa Ankle Rules were successfully applied by nurses without missing a fracture (as indicated by failure to reattend the $A \& E$ department or the trauma service).

By extending their use to nurses, the advantage of the rules-that is, the ordering of appropriate $x$ rays-can be applied earlier, before the patient is seen by the doctor, thus shortening times spent in $A \& E$ departments without missing significant fractures. The frequency of nurse ordered $x$ rays was less than that of physicians in the Canadian hospitals studied before the implementation of the rules. $^{9}$

We would like to acknowledge the help of the nurses who participated in this study and made it possible: Debbie Lee, Nick Armstrong, Mike Paynter, Nigel Wilkins, Raoul Chandrasakera.
1 Brand DA, Frazier WH, Kohliepp WC, Shea KM, Hoefer AM, Ecker MD, et al. A protocol for selecting patients with injured extremities who need $x$ rays. $\mathrm{N}$ Engl J Med. 1982;306:333-9.

2 Dunlop MG, Beattie TF, White GK, Raab GM, Doull RI Guidelines for the selective radiological assessment of inversion ankle injuries. BMJ 1986;293:603-5.

3 Lloyd S. Selective radiographic assessment of acute ankle injuries in the emergency department: barriers to implementation. Can Med Assoc J 1986;135:973-4.

4 Gleadhill DNS, Thomson JY, Simms P. Can more efficient use be made of $x$ ray examinations in the accident and emergency department? BMJ 1987;294:943-7.

5 Steill IG, McDowell I, Nair RC, Acta A, Greenberg GH, McKnight RD, et al. Use of radiography in acute ankle injuries: physicians attitudes and practice. Can Med Assoc J 1992;147:1671-8.

6 McCraig LF. National hospital ambulatory medical care survey: 1992 emergency department summary. Advance Data $1994 ; 245: 1-12$

7 Steill IG, Greenberg GH, McKnight RD, Nair RC, McDowell I, Worthington JR. A study to develop clinical decision rules for the use of radiography in acute ankle injuries. Ann Emerg Med 1992;21:384-90.

8 Steill IG, McKnight RD, Greenberg GH, Nair RC McDowell I, Wallace GJ. Interobserver agreement in the examination of acute ankle injury patients. Am J Emerg Med 1992;10:14-17.

9 Steill IG, Greenberg GH, McKnight RD,. Nair RC, McDowell I, Reardon M, et al. Decision rules for the use of radiography in acute ankle injuries; refinement and prospective validation. JAMA 1993;269:1127-32.

10 Steill I, Wells G, Laupacis A, Brison R, Verbeek R, Vandemheen $\mathrm{K}$, et al. Multicentre trial to introduce the Ottawa Ankle Rules for the use of radiography in acute ankle injuries. BMJ 1995;311:594-7.

11 Steill IG, McKnight RD, Greenberg GH, McDowell I, Nair RC, Wells GA, et al. Implementation of the Ottawa Ankle Rules. JAMA 1994;271:827-32.

\section{Referees for the Fournal of Accident $\mathcal{E}$ Emergency Medicine}

All papers submitted for publication in the Journal of Accident \& Emergency Medicine undergo peer review. As a result of the continuing rise in the number of papers received the Journal seeks additional referees.

This is an interesting and stimulating activity. The Editorial Office ensures that the workload for referees is not onerous and guidelines are provided to allow a structured critique of each paper. Referees are expected to return comments within three weeks of receipt of the manuscript.

Please contact the Editor, Journal of Accident \& Emergency Medicine at BMA House, Tavistock Square, London WC1H 9JR, telephone 0171-383-6795, fax. 0171-383-6668, stating your present appointment and any areas of special expertise. Reviewers are particularly welcome from other specialties with an interest in Emergency Medicine and from outside the U.K. 